\title{
LOS ESPACIOS PERIURBANOS EN EL ÁREA DE ALICANTE-ELCHE (ESPAÑA)*
}

\author{
V. Gozálvez Pérez; G. Ponce Herrero; J. Costa Más; \\ G. Canales Martínez; J. R. Navarro Vera
}

\begin{abstract}
RESUMEN
Los procesos de periurbanización en Alicante y Elche se iniciaron con los años 1960 y desde entonces han mantenido una expansión continua y acelerada; están basados en la industrialización y el desarrollo terciario locales, sobre los que ha confluido una importante edificación turístico-residencial en la franja costera. Se distinguen tres tipologías de periurbanización según morfologías edificatorias y de usos: 1) turístico-residencial en la franja costera, para propietarios locales y foráneos: 2) con viviendas unifamiliares en los espacios no costeros, para propietarios locales; en su mayor parte esta periurbanización ha ocupado suelos agrícolas arbolados; 3 ) ejes industriales y terciarios sobre las carreteras principales que parten de las ciudades.
\end{abstract}

\section{RÉSUMÉ}

Les processus de périurbanisation à Alicante et Elche ont commencé aux années 1960 et depuis ils ont poursuivi leur expansión accélérée; ils s'appuient sur l'industrialisation et le développement tertiaire local, sur lesquels une importante édification touristique-résidentiel dans la frange côtière s'est ajoutée. On distingue trois typologies de périurbanisation d'après les morphologies de l'edification et de l'utilisation: 1) touristique-résidentiel dans la frange côtière, pour les propiétaires locaux et d'ailleurs; 2) avec des pavillons dans les zones non côtières, pour les propietaires locaux; dans sa plupart cette périurbanisation a occupé des espaces agricoles arborisés; 3 ) les axes industriels et tertiaires sur les routes principales qui commencent dans les villes.

Las ciudades de Alicante y Elche, aunque separadas por menos de $20 \mathrm{~km}$, han experimentado una evolución secular desconectada; sus economías básicas han sido, en efecto, bien diferentes: terciaria la de Alicante, muy ligada tradicionalmente a su puerto, y, desde

* Comunicación presentada al Coloquio «Les territoires du périurbain des villes de la Méditerranée septentrionale». Aix-en-Provence, 28-30 septiembre 1992, organizado por Centre d'Etudes Géographiques des Transformations des Régions Méditerranéennes, Institut de Géographie, Université d'Aix-Marseille II. 
1833, a sus funciones de capital de provincia. Elche sentó su desarrollo en la agricultura y en la industria-artesanía, pero durante la segunda mitad del siglo XX es la industria, el quehacer que se identifica con la ciudad.

El fenómeno de la periurbanización se inicia y despliega con fuerza alrededor de ambas ciudades desde principios de los años 1960, yendo ligado a un cambio drástico en sus desarrollos económicos. Hasta esa fecha la emigración neta es una constante; desde 1960 casi todos los núcleos urbanos de la provincia experimentan una rápida expansión basada bien en la industrialización bien en los efectos del turismo litoral, sectores ambos desencadenantes de cuantiosos saldos inmigratorios con origen en las regiones meridionales de la península.

Durante largo tiempo los modelos de periurbanización acuñados en torno a Alicante y Elche han sido muy similares, y sólo contrastaban nítidamente en lo que atañe a la importancia de los usos industriales. Sin embargo, en la actualidad los espacios periurbanos de ambas ciudades evolucionan hacia su integración, fenómeno este a cuya plasmación contribuye el reciente diseño de macroproyectos de ordenación territorial en los que pese a converger iniciativas privadas e institucionales, sin embargo no han despejado dudas y temores respecto a hipotéticas operaciones especulativas y a la ocupación desorganizada del territorio, con desprecio de los valores paisajísticos y medio ambientales, que han sido casi norma durante las últimas décadas.

\section{Los entornos económico-demográficos}

La provincia de Alicante forma parte del litoral mediterráneo español, caracterizado por ser una de las áreas de España con mayor vitalidad demográfica durante las últimas décadas; en el intercensal 1986-1991 Alicante es la provincia española con mayor incremento relativo $(6,3 \%)$ y la cuarta en cifras absolutas $(+79.625$ habitantes sobre un censo de 1.334.545).

En el territorio provincial (228 habitantes $\left./ \mathrm{km}^{2}\right)$ son discernibles actualmente tres grandes espacios económico-demográficos (fig. 1), que han tenido dinamismos bien distintos durante los últimos 30 años (1960-1991): a) la franja turístico-litoral, con más de $200 \mathrm{~km}$ de recorrido, ha alcanzado los crecimientos más altos y regulares, generalmente superiores al 2-3\% anual y densidades en 1991 de 300 a 600 habit. $/ \mathrm{km}^{2}$; la inmigración, de trabajadores y de residentes no activos, ha sido el componente principal del aumento poblacional. En esta región turística predominan las actividades terciarias. b) Área con predominio de actividades industriales, se extiende por el valle del Vinalopó y comarcas contiguas que gravitan hacia la ciudad de Alcoy: el calzado, juguete y textil son sus industrias más destacadas. Debido a su especialización industrial este espacio presenta incrementos demográficos dispares: entre 1960 y 1975 — desarrollo industrial, inmigración - fueron tan importantes o más que en el litoral; después de 1975 — crisis industrial — el crecimiento se apoya sólo en el balance natural, relativamente vigoroso debido a la inmigración natalista acumulada. Alguna de sus ciudades más importantes, como Alcoy (64.579 habitantes en 1991), incluso ha padecido una ligera disminución censal en la última década. c) Espacios económicos relacionados con la agricultura, si bien este sector ha perdido su influencia económica, sustituido por empleos secundarios y terciarios, ejercidos en la propia localidad (reciente difusión industrial, a menudo acompañada de trabajo clandestino) o mediante desplazamientos diarios a los núcleos litorales (construcción, terciario) y a los industriales. Este tercer espacio lo conforman los pequeños asentamientos de montaña, al NE de la provincia, y los del regadío intensivo del Bajo Segura, al sur. 
Figura 1. Provincia de Alicante. Sectores de actividad predominantes en los municipios (año 1981). Los puntos gruesos en el centro del círculo indican porcentajes superiores al $55 \%$ en el sector I, y superiores al $70 \%$ en el II y III. T, franja turístico-litoral; In, área con predominio de actividades industriales; Am, área de agricultura de montaña; Ar, área de agricultura de regadío. En rayado, área estudiada.

La franja litoral y las comarcas industriales del interior son actualmente espacios de marcado carácter urbano — por actividades, tamaño de los núcleos — donde se han originado activos procesos de periurbanización después de 1960. Las excelentes condiciones climáticas y medioambientales del litoral alicantino, la cómoda cobertura de la red de transporte, el nivel de renta, el bajo o nulo valor agrícola tradicional de muchos espacios agrícolas, el minifundismo en la propiedad del suelo, el fuerte desarrollo de la agricultura a tiempo parcial, el dinamismo de la especulación, etc., son elementos que han favorecido un vigoroso desarrollo de la urbanización periurbana y litoral.

No obstante, en los últimos años también son denunciados problemas graves que aconsejan limitar y/o regular más severamente la ampliación de suelo urbanizado ( $v . g r$. falta de agua, densificación excesiva,...), mientras que la legislación autonómica y una inicial concienciación popular, intentan defender los espacios de interés paisajístico, científico y medioambiental que existen en el área de estudio y que se «interponen a» y/o «atraen» las urbanizaciones ( $v . g r$. acantilados de la Serra de Santa Pola o los espacios húmedos litorales). 
FIGURA 2. Distribución actual de las principales masas de cultivos en el área estudiada: 1, viñedo y secanos; 2, arbolado con regadío deficitario; 3, herbáceos de regadio; 4, uva de mesa; 5, cultivos intensivos.

El área urbana de Alicante-Elche se localiza sobre la confluencia de los dos ejes económico-demográficos más activos de la provincia: el corredor industrial del Vinalopó y la franja turístico-residencial del litoral (fig. 1). Este área queda conformada por 11 municipios que totalizan $960 \mathrm{~km}^{2}$; en 1960 censaba 242.010 habitantes de hecho, incrementados a 571.918 en 1991 (600 habit. $\left./ \mathrm{km}^{2}\right)$. 
Si en 1960 nadie ponía en duda la «división» de este territorio en dos comarcas históricas, Bajo Vinalopó, con capital en Elche, y Campo de Alicante o l'Alacantí (capital en Alicante), actualmente se tiende a acelerar la integración de esta dualidad como un espacio urbano único, aunque bipolar por el tamaño y distintas especializaciones económicas de sus dos ciudades principales: Alicante, que censa 275.111 habitantes en 1991 (121.527 en 1960), y Elche 187.596 (73.320 en 1960); en la primera tienen ocupación terciaria el 69,5\% de sus activos (año 1981), mientras en Elche el 59\% trabaja en el sector secundario.

La delimitación del área urbana actual (sobre fronteras municipales) se ha establecido atendiendo a la continuidad del espacio urbanizado (vid. figs. 4 y 8). Modestos relieves al norte e interior, limitan con cierta nitidez la periferia urbanizada, bien que tales barreras sean fácilmente franqueables, como de hecho ya sucede en la costa norte o en dirección a los núcleos rurales interiores de Aigües y Busot. El límite meridional del continuo urbanizado se detiene en el borde de las zonas húmedas de las Salinas de Santa Pola o Albufera de Elche (2.496 ha) y laguna de El Hondo de Elche (2.387 ha), espacios incluidos por España en la Convención de Ramsar (año 1989) y declarados «Paraje Natural» por el gobierno autonómico regional (1989).

\section{Modelo de usos del territorio}

El abanico de actividades económicas existente en el área, amalgamado con la estructura física, con el poblamiento y sobre todo con las infraestructuras de comunicación, configura un modelo territorial que, en la perspectiva de conjunto y dejando de lado la agricultura, se define por una especialización de espacios muy contrastada entre el interior y el litoral. El segundo viene signado por la presencia de un gran núcleo de base terciaria, Alicante, del que parten dos tentáculos pegados a la costa cuya vocación inminente es la de orden turístico-residencial, si bien la plasmación de la misma es claramente disimétrica. En efecto, el brazo septentrional atiende a una franja continua - al menos hasta El Campello - de despliegues edilicios en polígonos — bloques en open planning - y en urbanizaciones de edificios unifamiliares, tendidos sobre la primera línea de mar (L'Albufereta, el Cap y la dilatada playa de Sant Joan-Mutxavista) y en sucesivas bandas paralelas sobre el segundo frente, y todo ello engranado a partir de unos núcleos, tradicionales pero dotados de un gran dinamismo, como son Sant Joan y El Campello. En el brazo meridional, mucho más heterogéneo y discontinuo, descuellan los desarrollos turístico-residenciales del núcleo de Santa Pola y sus playas.

Por su parte, el territorio «interior» queda notoriamente decantado hacia los desarrollos industriales, y así cuenta con un gran núcleo como Elche, que ha pasado por la etapa de plaza agrocomercial (s. XIX) para devenir, por vía endógena, en polo industrial, bien que con un discreto grado de terciarización (explicable por su amplia base demográfica, su condición de cabeza «comarcal» y la incorporación de «terciario industrial»); a escasa distancia y en su órbita de influencia destaca otro polo fabril, Crevillente; mientras que en l'Alacantí también se interioriza la industria, que es la razón de ser de Sant Vicent, emplazado al NW de Alicante, en tanto que las principales áreas industriales de la capital se alejan del mar por la carretera de Madrid, sin olvidar que más adentro Agost desenvuelve un sector cerámico de cierto relieve. Además entre muchos de los asentamientos aparecen tendidos unos ejes radiales de actividad a modo de corredores tipo ribbon (cinta), los cuales sesgan los respectivos periurbanos con su maridaje de usos de signo comercial, servicial y fabril, al tiempo que materializan las conurbaciones, en ciernes, de l'Horta 
FiguRA 3. Área de Alicante-Elche. Espacio urbanizado (manchas en negro) según fotografía aérea de 1956.

(Alicante, por la cinta N-332, con Sant Joan y El Campello), de Alicante con Sant Vicent (ésta ya prácticamente consumada), y de Elche con Crevillente (por la N-340). Incluso cabría poner en consideración otros dos ribbon, aunque atípicos, de la carretera A-191 por la costa norte, cinta de engarce de un rosario turístico (residencial y servicial terciario), y la unión de Elche-Santa Pola, que merece ser resaltada por la densidad con que vertebra el fenómeno de la segunda residencia. 
FiguRA 4. Área de Alicante-Elche. En negro, suelo urbano y urbanizable, según los planes de urbanismo municipales en vigor (1992).

Por último, entre todos estos espacios se desenvuelven las actividades agrícolas y los espacios libres (naturales o menos). L'Horta d'Alacant tiene cada vez un sesgo más residual, mientras que la agricultura activa casi se limita a explotaciones intensificadas que se distribuyen en anillo discontinuo en torno a los espacios urbanizados (fig. 2). Aquí se incluyen las grandes compañías cosechero-exportadores, entre las que destaca Bony S.A., dedicada fundamentalmente a hortalizas, en especial tomate extratemprano, y localizadas 
sobre antiguos secanos transformados (Mutxamel, Busot, El Campello y Alicante). Más reciente es la aparición de cultivos forzados bajo plástico (hortalizas, flores), con lo que se busca alternativas de superación a una crisis agrícola vinculada al minifundismo y cultivos de menguada rentabilidad (almendro, cítricos, hortalizas). Aunque es relativamente reciente, el cultivo de uva de mesa hoy también está en crisis.

El más vasto continuo «abierto» está al sur de Alicante, es decir, los amplios regadíos deficitarios de Elche-Crevillente, cuya parte comprendida entre Alicante, Elche y Santa Pola, ofrece una serie de rentas de situación demasiado apetecibles como para no desatar diversos planes que conllevarán reclasificaciones amplias de suelo. Esta extensa zona agrícola-rural de Elche-Crevillente, que ocupa el glacis entre los relieves interiores y las zonas palustres litorales, tiene una morfología agraria dominada por el minifundismo y una distribución de cultivos conforme a la calidad de los suelos, a la disponibilidad de agua de riego y a los riesgos de helada por inversión térmica: así, por debajo de los 40 metros s.n.m., sobre todo en la parte central del cono aluvial del Vinalopó, dominan los cultivos herbáceos de regadío, mientras a mayor altitud, así como sobre los suelos menos desarrollados en los laterales del glacis, el almendro es casi monocultivo, salpicado por plantaciones de cítricos, aunque la palmera es el cultivo «típico» y casi simbólico de esta comarca; además de los palmerales densos en torno a la ciudad de Elche y junto a las zonas palustres, la palmera dispersa o en pequeñas agrupaciones es omnipresente en el paisaje.

\section{Indicadores del proceso de periurbanización}

El proceso de periurbanización del área Alicante-Elche se inició y desarrolló con rapidez después de 1960, apoyado en sus ventajas de localización y de crecimiento económico. Los planos que muestran los espacios urbanizados en 1956 y 1991 son bien ilustrativos de la intensidad de dicho proceso.

Un indicador ilustrativo de la vitalidad urbanizadora es el número de viviendas familiares: en 1960 el área estudiada censaba 64.468 viviendas, que daban una ocupación de 3,8 habitantes/vivienda, media reiterada en cada uno de los municipios. En 1991 las viviendas (289.379) se habían multiplicado por 4,5, mientras la población lo hacía por 2,4; la ocupación oscila ahora entre 2,5 habit./vivienda en Elche, y mínimos en los municipios más litorales: 0,7 en El Campello y 0,6 en Santa Pola.

\section{INCREMENTOS DE POBLACIÓN Y VIVIENDAS EN EL ÁREA URBANA DE ALICANTE-ELCHE}

\begin{tabular}{|c|c|c|c|c|}
\hline & \multicolumn{2}{|c|}{ Población } & \multicolumn{2}{|c|}{ Viviendas familiares } \\
\hline & anual $(\%)$ & habitantes & anual $(\%)$ & viviendas \\
\hline $1960-1970$ & 5,4 & 130.957 & 12,9 & 83.053 \\
\hline 1970-1981 & 3,1 & 129.374 & 5,6 & 82.387 \\
\hline $1981-1991$ & 1,4 & 69.577 & 2,6 & 59.467 \\
\hline
\end{tabular}

Fuente: INE, Censo de Población, Nomenclátor; Censo de viviendas de 1991.

Los espectaculares crecimientos que muestran las cifras del cuadro, especialmente en la edificación residencial, se explican por la superposición de un doble impulso, el industrial y el turístico-residencial, bien que una y otra causa no suelen coincidir sobre los mismos 
MUNICIPIOS DEL ÁREA URBANA DE ALICANTE-ELCHE. INCREMENTOS

ANUALES MEDIOS (\%)

\begin{tabular}{|c|c|c|c|}
\hline & $1960-70$ & 1970-81 & 1981-91 \\
\hline \multicolumn{4}{|l|}{ Alicante } \\
\hline Habitantes & 5,2 & 3,6 & 0,9 \\
\hline Viviendas & 13,1 & 4,4 & 1,6 \\
\hline \multicolumn{4}{|l|}{ Elche } \\
\hline Habitantes & 6,7 & 3,3 & 1,5 \\
\hline Viviendas & 11,1 & 6,0 & 2,1 \\
\hline \multicolumn{4}{|c|}{ Municipios residenciales ${ }^{(1)}$} \\
\hline Habitantes & 5,2 & 4,2 & 3,0 \\
\hline Viviendas & 19,5 & 8,2 & 5,9 \\
\hline \multicolumn{4}{|c|}{ Municipios industriales periféricos ${ }^{(2)}$} \\
\hline Habitantes & 2,2 & 2,1 & 0,8 \\
\hline Viviendas & 7,1 & 7,7 & 2,4 \\
\hline \multicolumn{4}{|c|}{ Municipios rurales $^{(3)}$} \\
\hline Habitantes & $-2,3$ & $-1,6$ & 3,2 \\
\hline Viviendas & 2,8 & 6,3 & 2,8 \\
\hline
\end{tabular}

(1) Municipios de El Campello, Mutxamel, Sant Joan, Sant Vicent y Santa Pola

(2) Agost y Crevillente.

(3) Aigües y Busot.

espacios. En efecto, las funciones económicas tan contrastadas entre los municipios del área estudiada son causa directa de las diferencias registradas en la cronología e intensidad de los incrementos locales.

Todos los ámbitos espaciales experimentan durante los años 1960 crecimientos espectaculares, aunque después aminoran su ritmo de expansión. El municipio de Alicante parece haber alcanzado, por el momento, un mayor grado de «saturación» relativa, pese a lo cual se anuncian nuevas y espectaculares urbanizaciones, que rellenarían amplios solares litorales (PAU junto a Playa de San Juan). Los municipios residenciales mantienen una elevada actividad constructora, con gran profusión de urbanizaciones, tanto con chalés individuales como más recientemente de «adosados». Los municipios rurales periféricos, experimentan en los últimos años una notable reactivación después de su anterior «vaciado» demográfico; es decir inician ahora un proceso que recuerda al que hace treinta años afectó a los municipios de la primera corona en torno a la ciudad de Alicante.

\section{Tipologías de periurbanización}

Según las morfologías edificatorias y de usos, en el área urbana de Alicante-Elche se diferencian tres tipologías básicas de periurbanización, cuya representación en cada ámbito espacial depende de las características socioeconómicas de las dos ciudades principales, pero también de las peculiaridades físicas de sus respectivos espacios periurbanos, de antiguos procesos de ocupación del suelo y de la red viaria, como elementos más influyentes. 
FiguRa 5. Área urbana de Alicante-Elche. Incrementos municipales de la población de hecho (línea continua) y viviendas familiares (línea discontinua) entre 1960 y 1991 (1960=100; para 1991 se indican, además, las cifras absolutas).

FUENTE: INE, Censos de habitantes y viviendas. 
Figura 6. Indicadores demográficos en el área urbana de Alicante-Elche y municipios próximos. 
FIGURA 7. Área urbana de Alicante-Elche. Año 1991. Distribución por municipios de las viviendas familiares según tipo de ocupación; las cifras indican el total de viviendas en cada sector. Fuente: INE, Censo de viviendas de 1991.

\section{4.a. La franja costera: periurbanización turístico-residencial}

La edificación de la franja costera adopta, en parte, características de ocupación periurbana, debido a su cercanía a las ciudades de Alicante (caso de las urbanizaciones de l'Albufereta, Playa de San Juan, El Campello) y de Elche (urbanizaciones de Santa Pola); fundamentalmente son viviendas secundarias, aunque la ocupación permanente gana importancia en el litoral periurbano de Alicante. Estos asentamientos adoptan forma lineal; frente a las playas de arena predominan los bloques de apartamentos, con frecuencia de diez o más plantas, mientras junto a las costas rocosas o con acantilados bajos son mayoría las urbanizaciones de chalés unifamiliares y de «adosados».

Las concentraciones de edificios más altos corresponden a los construidos en el período 1965-80, mientras durante la última década la disminución de alturas y proliferación de adosados sólo aparentemente rebajan las densidades. Una y otra morfología de edificación litoral se realizan como ensanches de núcleos urbanos anteriores (v. gr. Santa Pola, El Campello) y sobre todo como urbanizaciones creadas ex-novo: l'Albufereta, Playa de San Juan, Arenales del Sol, etc.

Los ejemplos primeros y más destacados de periurbanización litoral son la Playa de San Juan y l'Albufereta. La construcción del primero — sobre 110 ha - se inició en 1960 y en 1982 había sumado 11.567 viviendas, distribuidas entre 126 chalés y 207 edificios de apartamentos, cuya mayoría alberga a unas 60-70 viviendas. Una encuesta realizada por T. Mazón en 1983 señala para este conjunto las siguientes características: la primera línea de apartamentos pertenece a la clase acomodada, y el resto a las clases media y media-baja; 
Figura 8. Área urbana de Alicante-Elche. Año 1992. Distribución esquemática de las tipologías de periurbanización. $C$, centro comercial; $H$, hospital universitario; $U$, Universidad; $F$, Recinto Ferial; A, aeropuerto. 
sólo un $11 \%$ de los apartamentos tenían ocupación permanente; la mayoría de propietarios reside en la vecina ciudad de Alicante, núcleos industriales del valle del Vinalopó, Albacete y Madrid, mientras son escasos los propietarios extranjeros. Según el Padrón de habitantes de 1981 ya tenían residencia permanente en Playa de San Juan 1.670 habitantes, sobre todo matrimonios jóvenes, y entre sus activos el $98 \%$ trabajaba en el sector terciario.

L'Albufereta es la urbanización litoral (años 1960) más densa y congestionada, tanto por la edificación en altura (la Torre Adoc alcanza 112 m, con 200 apartamentos), como por la falta de espacio entre el escarpe de la Serra Grossa y el mar; su playa de arenas se reduce al pequeño cordón que cierra la desembocadura del barranco de Maldo, que en tiempos históricos originó aquí una charca o pequeña albufera, que perdura en el topónimo actual. Inicialmente abundaron los compradores extranjeros (Vera, 1987), en parte procedentes de antiguas colonias africanas (pieds-noirs, belgas). Entre l'Albufereta y Playa de San Juan se extiende la urbanización del Cap de l'Horta, donde la presencia de un Instituto de Enseñanza Media resalta el grado de ocupación permanente de estas urbanizaciones.

La edificación turístico-residencial de Santa Pola es el ejemplo más nítido de urbanización litoral como ensanche de núcleo tradicional, y en parte está condicionado por la geomorfología de su entorno: hacia el sur la edificación ocupa la amplia restinga de la albufera-salinas, aunque en los últimos años la urbanización también invade parte de esta zona húmeda mediante su relleno. En los años 1960-70 se edificó con bloques de apartamentos de 4-5 alturas y planta diáfana, aunque en los espacios más cercanos al núcleo tradicional, la densificación es muy alta; sobre el relleno de la albufera han proliferado chalés adosados de dos plantas y baja calidad.

Al norte del núcleo de Santa Pola la edificación ocupó primero el estrecho glacis entre la Serra de Santa Pola y el mar, aquí de costa rocosa hasta su reciente artificialización con espigones que han propiciado el relleno de arena: entre 1960 y 1975 proliferaron los chalés de cierta prestancia, en su mayor parte pertenecientes a industriales de Elche; después de 1985 se ha intensificado la edificación detrás de la primera línea, encaramándose por los bellos acantilados de la Serra, hasta formar un paradigma de destrucción paisajística, densificación y construcción antiestética.

En 1991 el municipio de Santa Pola censaba 25.418 viviendas, de las que sólo el 17\% tenía ocupación principal. Los veraneantes de Santa Pola han sido tradicionalmente los vecinos de la ciudad de Elche, a cuyo municipio perteneció Santa Pola hasta 1835, pero en la actualidad recibe grandes contingentes de los municipios industriales del valle del Vinalopó, de Madrid y, más recientemente desde el País Vasco.

Los más de $7 \mathrm{~km}$ de franja costera entre la Serra de Santa Pola y la N-340 son un espacio de alto interés paisajístico y científico — varios niveles de playas fósiles cuaternarias, campos de dunas, zonas húmedas litorales en avanzado proceso de colmatación, laderas de la Serra de Santa Pola,...-. Pese a su atractivo natural, que ya atrajo las primeras ocupaciones residenciales en los años 1960 (Arenales del Sol), su edificación más intensa es posterior a 1975, una vez que han sido saturadas las áreas costeras tradicionales de influencia de Alicante, hacia el norte de la ciudad, y de Elche, hacia los ensanches de Santa Pola. Se trata aquí de urbanizaciones de gran superficie — propiedad del suelo más extensa dado su escaso o nulo valor agrícola-, tanto las ejecutadas o en proceso de hacerlo (Gran Alacant, sobre 470 ha, Arenales del Sol sobre 342 ha), como las propuestas sobre los espacios húmedos del Clot de Galvany y antigua albufera de Agua Amarga (200 ha) que ha visto rechazados o paralizados dos grandes proyectos muy similares en 1976 (Plan Lucentia) y 1988 (Urbanización Marina Blanca). No obstante, el proyecto urbanístico «El Triángulo Alicante-Elche-Santa Pola» diseñado en 1992, insiste para esta franja costera con un «Parque Regional de los Arenales» y el contiguo «Hábitat del Clot de Galvany». 
En la zona de estudio se individualizan dos grandes áreas con esta tipología de periurbanización laxa, en torno a las ciudades de Alicante y de Elche. La primera se extiende por el propio municipio de la capital y los contiguos de Sant Joan, El Campello, Mutxamel y Sant Vicent, es decir lo que en la actualidad ya es una pequeña área metropolitana consolidada; muy recientemente esta urbanización también penetra en los términos de Busot, Aigües y, más tímidamente, en las zonas más próximas del municipio de Elche.

Esta periurbanización laxa está formada por viviendas unifamiliares, entre las que primero abundaron las dispersas, después las agrupadas en «urbanizaciones» y más recientemente (años 1980) también en forma de chalés adosados, que así abaratan los costes de una demanda en auge. Esta ocupación residencial difusa se ha multiplicado de forma espectacular sobre la que fue huerta arbolada de Alicante, los secanos contiguos y más recientemente sobre los espacios periféricos no cultivados. A diferencia de la franja costera, donde los propietarios foráneos a la comarca tienen gran peso, la periurbanización de las zonas no costeras suele estar vinculada a la ciudad de Alicante, bien como segunda residencia, bien como vivienda principal. De modo que mientras en El Campello, municipio con dilatada franja costera, gozan de ocupación principal sólo el 23\% de sus viviendas (censo de 1991), en Mutxamel son el 53\%, en Sant Joan el 56\% y en Sant Vicent el 61\%.

Sobre la antigua huerta de Alicante, los asentamientos espontáneos de vivienda unifamiliar constituyen auténticas constelaciones de rurbanización, de modo que la actividad agrícola queda aquí muy limitada; el minifundismo parcelario y la tupida malla caminera de los espacios agrícolas han facilitado tales ocupaciones espontáneas en épocas poco exigentes para este tipo de edificación. Esta omnipresente ocupación residencial de baja densidad sobre la antigua huerta de Alicante, tiene un antiguo precedente en los numerosos palacetes o casonas que la burguesía de la capital edificó en la «huerta», desde las llamativas casas con torre defensiva (ss. XVI-XVIII) a las de arquitectura modernista de principios del siglo XX.

En Elche la periurbanización con residencia unifamiliar ocupa un extenso y difuminado espacio a partir del primer anillo periurbano, compacto y estrecho, ocupado por la industria.

Los espacios residenciales periurbanos de Elche adoptan una distribución similar a los de la ciudad de Alicante, es decir, una parte se localiza sobre la costa, con edificación en altura y «adosados» más recientemente (Santa Pola, Arenales del Sol), mientras el periurbano residencial unifamiliar se extiende por los espacios agrícolas de su extenso municipio, en chalés dispersos o agrupados en urbanizaciones. En ambos casos esta ocupación de segunda residencia ha sido facilitada por el minifundismo agrario, cultivos tradicionales no competitivos, densa red caminera, atractivo paisajístico derivado del arbolado y topografía en glacis o colinas, entre otros factores.

La mayor superficie agrícola de Elche y su menor volumen demográfico han posibilitado que los espacios agrícolas tradicionales más intensivos y con mayor densidad de poblamiento agrícola - esto es, los centrados en el cono aluvial del Vinalopó entre los 10 y 40 metros s.n.m.- ofrezcan una ocupación periurbana aún exigua. Esta es, en cambio, más intensa en las áreas rurales con regadío más deficitario o nulo, cubiertas de abundante arbolado (almendros). En concreto la periurbanización más intensa se extiende en los márgenes de la carretera C-3317 entre Elche y Santa Pola, y en la contigua área enmarcada por las nacionales N-340, N-332 y aeropuerto, donde también llegan los propietarios de la capital. Esta extensa zona de 5.500 hectáreas constituye centro de interés del proyecto 
urbanístico de iniciativa privada «El Triángulo Alicante-Elche-Santa Pola» el cual la rebautiza como Centuria Rural, en «honor» a la Centuriatio romana de Ilici, que parcelaba estas tierras; para dicho proyecto «La vocación identificada (para la Centuria Rural) es la de mantenimiento del carácter del campo de Elche y mejora paisajística», para lo que «propone detener el proceso espontáneo de densificación de este territorio», pero conjugándolo — según los paneles y guía de la exposición sobre este proyecto- con la creación de ocho nuevos núcleos residenciales y una notable gama hospitalaria (4 hospitales, residencia de ancianos, ciudades y hogares para la tercera edad,...); obviamente también contempla «completar y mallar la red viaria actual».

M. Sevilla (1985, 305-319) señala la segunda mitad de los años 1960 como inicio de la fase expansiva de la segunda residencia en Elche, y para 1980 estima en 6.000 el número de chalés, los que suponían una ocupación residencial rururbana de 1.200 hectáreas (parcela mínima $2.000 \mathrm{~m}^{2}$ ), en contraste con las 730 ha de suelo urbano de Elche. Las urbanizaciones o parcelaciones ejecutadas durante el período 1975-79 ascienden a 54, con una superficie de 283 ha para 962 chalés; todas ellas se hicieron al amparo de una notable permisividad municipal (sin tramitación del Plan Parcial). La alta permisividad en la urbanización rural del campo de Elche termina en 1979, con el gobierno municipal socialista (en 1979 el Ayuntamiento de Elche otorgó 935 licencias para la construcción de chalés, 201 en 1980), lo que originó una agria polémica en la que los agricultores se alinean a favor de la urbanización rural (propiedad agrícola escasa, regadío muy deficitario, fuerte impulso industrial). Entre los medios para detener la urbanización rural, el Ayuntamiento impuso parcela mínima de $5.000 \mathrm{~m}^{2}$ y en la Revisión del PGOU de 1984 aquélla se elevó a $10.000 \mathrm{~m}^{2}$ en zona de regadío y a $25.000 \mathrm{~m}^{2}$ en tierras de secano. Por otra parte, la Revisión también contempla 22 áreas ya parceladas susceptibles de Planes Especiales de mejora del medio rural, que en conjunto suman 1.048 hectáreas en las que ya existen 2.156 viviendas y quedan vacantes 1.873 parcelas.

\section{4.c. Los ejes industriales y terciarios}

Los espacios periurbanos industriales de la ciudad de Alicante se localizan casi en su totalidad al sur de la conurbación Alicante-Sant Vicent, apoyados sobre las carreteras principales, de cómoda accesibilidad. Varios son los casos: 1) Los espacios industriales más extensos bordean la N-330 (autovía hacia Madrid), con polígonos tanto espontáneos en contacto con los barrios periféricos de la ciudad (La Florida), como planificados y separados de ella (Pla de la Vallonga, Las Atalayas), donde predominan las actividades de almacenamiento y distribución de productos. Este «eje industrial» sobre la N-330 es, sin duda, el que goza de mejor situación para ser potenciado, debido a su vecindad con el cruce de la autovía N-330 y la autopista A-7, a que su línea de expansión es opuesta a la costa, así como por su entorno «repulsivo» para la ocupación residencial (cercanía a la cárcel provincial, fábrica de cementos). 2) La carretera entre Alicante y Sant Vicent sirvió para localizar importantes industrias cerámicas a principios de siglo. En la actualidad, ya desaparecidas tales industrias, evoluciona con rapidez hacia usos más acordes con su centralidad actual, atrayendo industrias no contaminantes, almacenes y usos terciarios (Universidad, comercios de gran superficie) 3) La carretera entre Sant Vicent y Agost, tiene en sus extremos sendas cintas industriales, cuyo desarrollo queda comprometido por la escasa accesibilidad actual. 4) La carretera N-340 también ha sido ocasión para localizaciones industriales al sur de la capital. Aunque por su recorrido junto al mar es un eje más apropiado para usos residenciales o terciarios, aquí se ubican las industrias más «duras» de 
la ciudad: INESPAL (aluminio), Manufacturas Metálicas Madrileñas S.A., Manville Española S.A. (tratamiento minerales), Butano S.A. (envasado y distribución), matadero municipal, etc.; todas ellas fueron instaladas durante los años 1960, mientras posteriormente predominan los almacenes y algún centro terciario. La vecindad del puerto y ferrocarril motivó, desde principios de siglo, la instalación aquí de grandes industrias relacionadas con estos medios de transporte (v. gr. CROS, S.A. en 1906, Unión Española, en 1910; ambas de fabricación de abonos), aunque la actual centralidad urbana de los solares de las últimas industrias deriva, lógicamente, a su ocupación residencial; en el extremo opuesto de este eje industrial que disfruta de excelentes paisajes, se ha instalado el Recinto Ferial, y se proyectan dotaciones terciarias en su entorno.

Mientras la ciudad de Alicante ha configurado sus espacios periurbanos con notable segregación de usos, residencial al norte e industrial «lineal» al sur, la ciudad de Elche queda casi envuelta por un anillo industrial, formado con polígonos (Altabix, Carrús), con sectores urbanos periféricos de tolerancia industrial, que a veces han derivado a «tolerancia residencial», así como por localizaciones industriales más o menos dispersas en suelo agrícola, favorecidas por el apretado haz de carreteras que de forma radial parten desde Elche.

No obstante, como expresa la fig. 8, en la actualidad la periurbanización industrial de Elche se orienta en tres direcciones, sobre sendos ejes viarios: hacia el norte, entre el barrio de Carrús y la autopista A-7, en contacto con la carretera C-3317 en dirección a Aspe; se trata de una amplia reserva de suelo industrial ya prevista en el PGOU de 1970. Las otras dos direcciones de periurbanización industrial siguen direcciones opuestas pero ambas apoyadas sobre la congestionada carretera N-340, que a su vez tienden al encuentro o a completar los ejes industriales que parten desde Alicante y desde Crevillente. Mientras sobre el segundo existe ya un continuo industrial — con enclaves comerciales cerca de Elche-, en dirección a Alicante se proyectan actualmente fuertes iniciativas industriales; estas vienen desde las previsiones de la Revisión del PGOU de Elche de 1984, pero con añadidos más recientes, como el polígono industrial de Torrellano, de iniciativa municipal, y las espectaculares propuestas del proyecto urbanístico del «Triángulo», denominadas «Ciudad Lineal de la Industria» (entre Elche y Torrellano, al norte de la N-340), que se prolongaría al norte del aeropuerto con un pretendido «Parque de Actividades Innovadoras del Mediterráneo».

Así pues, la intensidad del periurbano industrial de Elche-Crevillente, que en gran parte encierra a los respectivos núcleos urbanos, refleja bien tanto la especialización económica de estas dos ciudades, como su crecimiento rápido y notable improvisación locacional, además de unas atenciones bien escasas a la calidad medioambiental (v. $g r$. barrancos $=$ vertederos).

Los procesos de periurbanización de Alicante y Elche se iniciaron con los años 1960, desde entonces y hasta la actualidad aquéllos han mantenido una expansión muy acelerada, y, además, al comienzo de los años 1990 se proyecta una renovación de su dinamismo.

Las bases económicas para tales procesos radican en la industrialización y el desarrollo terciario locales, sobre los que ha confluido una importante edificación turístico-residencial en la franja costera también para usuarios foráneos. Las bondades climáticas, la favorable configuración topográfica, la convergencia de infraestructuras de transporte, dominio del paisaje agrícola minifundista, de arbolado y de regadío deficitario, aumento del nivel de vida, permisividad en la edificación laxa, etc. se han sumado para alcanzar una 
intensa ocupación periurbana en torno a ambas ciudades que continúa en expansión a partir de las tres tipologías de periurbanización ya configuradas; el mayor crecimiento corresponde a los espacios residenciales, mientras el de usos terciarios es más reciente.

La tradicional desconexión y divergencia en las dinámicas de crecimiento urbano de Alicante y Elche ha permitido la «supervivencia» de amplios espacios abiertos entre ellas, pese a la acumulación aquí de sobresalientes ventajas objetivas. Estos espacios periurbanos son los que actualmente centran la atención de los proyectos urbanísticos más ambiciosos, tanto de iniciativa privada como institucional, cuyo objetivo sería impulsar un gran centro de desarrollo económico, apoyado en el entorno urbano y de infraestructuras, existentes o en proyecto; los usos del suelo a que se daría cabida incluyen los residenciales, industriales, terciarios y el turístico-lúdico sobre la franja más costera, en cualquier caso con perspectivas de grandes superficies y realizaciones para cada uno de ellos; la crisis actual de crecimiento industrial en la provincia de Alicante y su revitalización a través de estos macroproyectos («El Triángulo Alicante-Elche-Santa Pola» o el «Plan Estratégico» auspiciado por la Diputación Provincial) parecen aunar voluntades en su apoyo.

Los crecientes problemas que provoca la densa ocupación urbanística de los espacios litorales (preservación del paisaje y del patrimonio natural y cultural, insuficiencia de recursos tan básicos como el agua, contaminaciones, etc.) han originado durante los últimos años la promulgación de variadas leyes estatales (Ley de Costas, en 1988) y autonómicas (Ley de Impacto Ambiental, Ley de Ordenación del Territorio de la Comunidad Valenciana, ambas en 1989; Ley sobre suelo no urbanizable, en 1992) que tratan de conseguir una planificación territorial más satisfactoria que la vigente. Los ejemplos de periurbanización que nos ocupan, en su realidad actual y en sus proyectos de nuevos impulsos, sin duda pueden y deberían ser buen «laboratorio» donde se verifique la efectividad de aquéllas, mediante el equilibrio entre las acciones para aumentar un deseable desarrollo económico y la preservación de las riquezas medioambientales y calidad de vida.

\section{Bibliografía}

CALVO PALACIOS, J. L. y PUEYO CAMPOS, A.: «La técnica de potenciales en el estudio del proceso de urbanización de la España peninsular (1970-1986)» ap. Los procesos de urbanización: siglos XIX y XX, Alicante, Instituto de Cultura Juan Gil-Albert, 1991, pp. 49-62.

GOZÁlveZ PÉREZ, V.: Santa Pola. Urbanismo. Economía. Población, Alicante, Círculo de Economía, 1976, $120 \mathrm{pp}$.

GOZÁLVEZ PÉREZ, V.; COSTA MAS, J., et al.: Atlas sociodemográfico de la ciudad de Alicante, Alicante, Instituto de Estudios Juan Gil-Albert, 1987, 143 pp.

GOZÁLVEZ PÉREZ, V.; COSTA MAS, J., et al.: Comarca l'Alacantí, Alicante, Mancomunidad de l'Alacantí, 1990, 248 pp.

MAZÓN, T.: La urbanización de la Playa de San Juan: un espacio turístico residencial, Alicante Instituto de Estudios Juan Gil-Albert, 1987, 147 pp.

SEVILLA JIMÉNEZ, M.: Crecimiento y urbanización. Elche 1960-1980, Universidad de Alicante y Ayuntamiento de Elche, 1985, 418 pp.

VARIOS: Libro Blanco del Turismo en la Costa Blanca, Alicante, Cámara de Comercio, Industria y Navegación, 1990, 2 t.

VARIOS: Actualidad y futuro de los espacios urbanos. Alicante, Universidad de Alicante, 1991, 189 pp. +8 planos f.t.

VARIOS: Alicante. Territorio, Alicante, Colegio de Ingenieros de Caminos, Canales y Puertos, 1992, $301 \mathrm{pp}$.

VARIOS: El Clot de Galvany d'Elx. Regeneració ecològica i utilització pública de les zones humides, Ajuntament d'Elx, 1992, 78 pp.

VERA REBOLLO, J. F.: Turismo y urbanización en el litoral alicantino, Alicante, Instituto de Estudios Juan Gil-Albert, 1987, 441 pp. 